
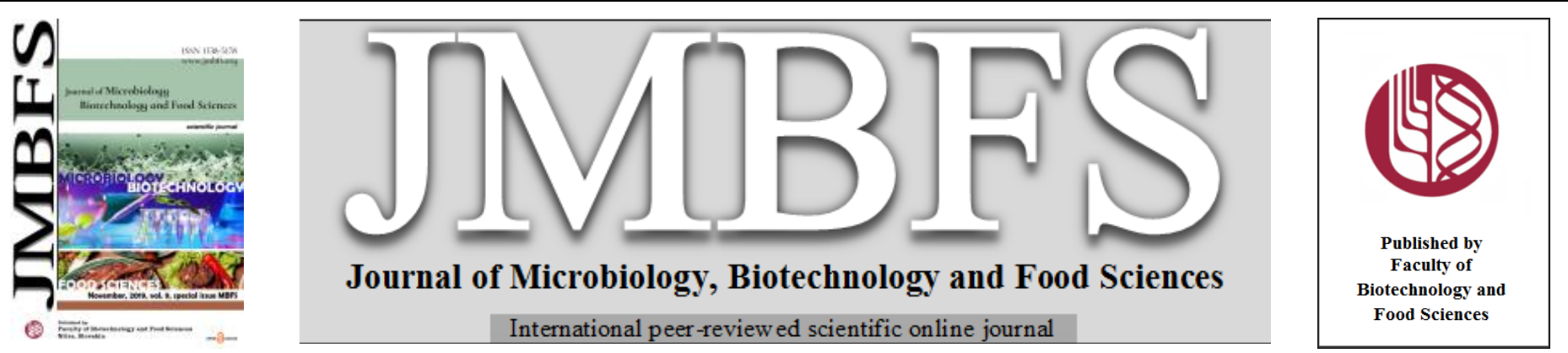

\title{
THE EFFECT OF RESVERATROL ON THE VITALITY OF MICE EPIDIDYMAL SPERMATOZOA
}

\author{
Eva Tvrdál ${ }^{*}$, Lucia Dianová ${ }^{1}$, Michal Ďuračka ${ }^{1}$, Róbert Kirchner ${ }^{2}$
}

\author{
Address(es): MSc. Eva Tvrdá, PhD \\ ${ }^{1}$ Department of Animal Physiology, Faculty of Biotechnology and Food Scinces, Slovak University of Agriculture in Nitra, Tr. A. Hlinku 2, 94976 Nitra, Slovakia, \\ phone number: 00421-37-641-4918. \\ ${ }^{2}$ University Vivarium, Botanical Garden, Slovak University of Agriculture in Nitra, Tr. A. Hlinku 2, 94976 Nitra, Slovakia.
}

*Corresponding author: evina.tvrda@gmail.com

doi: 10.15414/jmbfs.2019.9.special.457-461

\section{ARTICLE INFO}

Received 11. 9. 2019

Revised 24. 10. 2019

Accepted 25. 10. 2019

Published 8. 11. 2019

Regular article

open 2 access

\begin{abstract}
The aim of this study was to investigate the effects of various concentrations of the natural polyphenol resveratrol (RES) on the vitality of mouse epididymal spermatozoa. In the experiments, concentrations of $0,5,10$ and $25 \mu \mathrm{mol} / \mathrm{L}$ were applied to the sperm incubation medium. Subsequently, sperm motility and viability analyses were performed at time $0 \mathrm{~h}$ and after $2 \mathrm{~h}$ of incubation at $37^{\circ} \mathrm{C}$. Sperm motility was analyzed by the computer-assisted semen analysis (CASA). The mitochondrial membrane potential was determined using the fluorescent dye JC-1. Membrane integrity was analyzed by fluorescence staining with carboxyfluorescein diacetate (CFDA), the acrosome integrity was assessed using the fluorescent peanut agglutinin (PNA) dye and we also evaluated the percentage of necrotic cells positive for the fluorescent dye propidium iodide (PI). Our results indicate a significant $(\mathrm{P}<0.05)$ increase of the sperm motility following the addition of $10 \mu \mathrm{mol} / \mathrm{L}$ RES at $0 \mathrm{~h}$ and also a significant increase after $2 \mathrm{~h}$ at $10 \mu \mathrm{mol} / \mathrm{L}(\mathrm{P}<0.01)$ and $25 \mu \mathrm{mol} / \mathrm{L}$ RES $(\mathrm{P}$ $<0.05)$ when compared to the control. At a RES concentration of $10 \mu \mathrm{mol} / \mathrm{L}$, the mitochondrial activity was significantly increased $(\mathrm{P}$ $<0.05$ ) after $2 \mathrm{~h}$. In the case of membrane integrity, no statistically significant changes were observed at time $0 \mathrm{~h}$, but after $2 \mathrm{~h}$ there was a significant $(\mathrm{P}<0.05)$ increase in the membrane integrity following the addition of $25 \mu \mathrm{mol} / \mathrm{L}$ and $10 \mu \mathrm{mol} / \mathrm{L}$ RES $(\mathrm{P}<0.01)$ in comparison with the control. There were no statistically significant results with respect to the percentage of PI-positive cells. The number of cells with an intact acrosome integrity at $0 \mathrm{~h}$ as well as $2 \mathrm{~h}$ was significantly $(\mathrm{P}<0.05)$ increased following the administration of $10 \mu \mathrm{mol} / \mathrm{L}$ RES. The results of our study show that low concentrations of resveratrol have protective effects on the epididymal spermatozoa of mice.
\end{abstract}

Keywords: spermatozoa, resveratrol, mouse, epididymis

\section{INTRODUCTION}

The house mouse (Mus musculus) has become the laboratory animal of choice as a model to study human biology and disease due to its phylogenetic and physiological similarity to humans, simple and effective laboratory maintenance and breeding, as well as the availability of a variety of inbred strains (Perlman, 2016). Genomic studies revealing prominent genetic homologies between both species (Mouse Genome Sequencing Consortium el al., 2001) together with the evolution of techniques for the development of knockout, knockin and transgenic mice, have provided powerful tools for contemporary research strategies, and have led to an impressive increase in the use of mice as model organisms to understand human biology on a new level (Bolker, 2012). Nevertheless, a standardized protocol for mouse sperm processing and cryopreservation is still under development for most strains. As such, a comprehensive methodology for better preservation procedures of mouse spermatozoa may become pivotal tools to increase the number of valuable genetic strains for further research and application (Takahashi and Liu, 2010).

The distribution of spermatozoa from a small number of males with superior genetic traits relies on thorough semen processing and preservation procedures Nevertheless, an extended exposure of spermatozoa to ex vivo conditions may lead to a continuous reduction of their survival, possibly due to oxidative stress developing during in vitro storage (Bansal and Bilaspuri, 2010). The overproduction of toxic reactive oxygen species (ROS), followed by alterations of the sperm motility and viability has been linked to sperm processing and in vitro incubation of male reproductive cells (Gibb and Aitken, 2016). Poor sperm survival has been associated with changes to the membrane architecture of male gametes caused by lipid peroxidation (LPO). Oxidative damage to mitochondria and flagellar structures may be a factor of major importance to explain the impaired motion behavior and fertilization ability of spermatozoa, and since the mitochondria located in the sperm mid-piece generate energy to support motility, changes in the mitochondrial membrane potential could be a good indicator of possible functional impairment of male gametes (Peña et al., 2009). When collected and manipulated in vitro, spermatozoa run the risk of being exposed to supra-physiological level of ROS, which is the main parameter to be considered in order to evaluate the extent of oxidative stress (du Plessis et al., 2008).

Investigations on the benefits of antioxidant supplementation on the sperm vitality has become a major spotlight in human and veterinary andrology (Bansal and Bilaspuri, 2010). This study focuses on the activity of resveratrol $(3,5,40$ trihydroxistilbene; RES), a polyphenol found in grapes, red wine, berries, plums, peanuts and pistachios (de la Rastra and Villegas, 2007). RES is well-known for its anti-inflammatory, antimicrobial and estrogenic properties (Gambini $\boldsymbol{e t}$ al., 2015). At the same time, RES has been shown to be a potent antioxidant, based on its ability to modulate the expression and activity of a multitude of antioxidant enzymes (Khan et al., 2013) and to inhibit lipid peroxidation (LPO) (Tadolini et al., 2000). A number of studies have shown that RES acts as a direct ROS quencher (Pandey and Rizvi, 2011) as well as a metal-chelating agent preventing the Fenton reaction (Tvrdá et al., 2015a).

With regards to male reproductive function, previous reports have revealed that RES stimulates and protects rabbit and murine spermatocytes and spermatozoa against LPO (Revel et al., 2001; Shi et al., 2008). It has also been reported that RES has the ability to reduce apoptosis in germinal cells (Revel et al., 2001) and to provide protection to the reproductive cells against environmental toxins (Jiang et al., 2008).

In vivo it has been demonstrated that RES supplementation enhances spermatogenesis by triggering the hypothalamic-pituitary-gonadal axis with no adverse effects (Juan $\boldsymbol{e t}$ al., 2005). At the same time RES administration may trigger penile erection and enhance testicular steroidogenesis, sperm count and epididymal sperm motility in rodents (Shi et al., 2008).

Summarizing the above-mentioned evidence, it may be noted that the data illustrating beneficial in vitro effects of RES on ejaculated spermatozoa are solid In our case, however, we focused to shed more light on the behavior of RES on spermatozoa collected from the epididymis. Specifically, the aim of this study 
was to investigate the in vitro effects of resveratrol on the motility, mitochondrial activity, membrane and acrosome integrity of mouse epididymal spermatozoa.

\section{MATERIAL AND METHODS}

\section{Animals and sample collection}

Male ICR mice $(n=20,120$ days old) obtained from the Institute of Experimental Pharmacology (Slovak Academy of Sciences, Dobrá Voda Slovakia) were kept in plastic cages at $24 \pm 1{ }^{\circ} \mathrm{C}$ and $12 \mathrm{~h}$ light $/ 12 \mathrm{~h}$ dark photoperiod. The animals were provided with a standard pellet laboratory feed and water ad libitum. Institutional and national guidelines for the care and use of laboratory animals were followed, and all procedures were approved by the State Veterinary and Food Institute of the Slovak Republic (no. 3398/11-221/3) and Ethics Committee.

The mice were euthanised by cervical dislocation, the reproductive organs were removed and deposited into a sterile Petri dish with fresh, ice-cold PBS (SigmaAldrich, St. Louis, USA). With the help of tweezers and a blade knife the epididymes were separated from the teses and washed twice in PBS. The cauda was cut into approx. $1.5 \mathrm{~cm}$ pieces, and placed into PBS without (control group) or with RES (Sigma-Aldrich, St. Louis, USA) previously dissolved in DMSO (dimethyl sulfoxide; Sigma-Aldrich, St. Louis, USA) and supplemented a various concentrations $(5,10,50 \mu \mathrm{mol} / \mathrm{L})$. Spermatozoa were allowed to swim out during $15 \mathrm{~min}$ at $37^{\circ} \mathrm{C}$. Specific analyses took place immediately following sperm collection and $2 \mathrm{~h}$ post-collection. Spermatozoa were kept at $37^{\circ} \mathrm{C}$ between the analyses.

\section{Sperm motility}

Spermatozoa motility was measured using the CASA (Computer Assisted Semen Analyzer) system - HTM IVOS (CASA; Version 14.0 TOX IVOS II.; HamiltonThorne, Beverly, USA). Each sample was placed into the Makler Counting Chamber (depth $10 \mathrm{~mm}$, Sefi-Medical Instruments, Haifa, Israel) and the percentage of motile spermatozoa (motility $>5 \mu \mathrm{m} / \mathrm{s}$; MOT) was evaluated. This study was performed in five replicates at each concentration and time of assessment. At least 300 spermatozoa were analyzed in each sample.

\section{Mitochondrial activity}

For the assessment of the mitochondrial membrane potential (MMP), $1 \times 10^{6}$ cells were transferred to an eppendorf tube and diluted to $100 \mu \mathrm{L}$ using PBS. Subsequently, $5 \mu \mathrm{L}$ of the cationic dye JC-1 (tetraethylbenzimidazolylcarbocyanine iodide; Cayman Chemical, Ann Arbor, USA) were added to each sample aliquot. The samples were incubated for 20 minutes at $37{ }^{\circ} \mathrm{C}$. Subsequently, the samples were centrifuged for 5 minutes at $2100 \mathrm{RPM}$ and the resulting pellet was washed with $100 \mu \mathrm{L}$ PBS. The centrifugation and washing step was repeated twice. two more times. The cells were diluted with $100 \mu \mathrm{L} \mathrm{PBS}$, transferred to a 96-well plate throughout and analyzed using the Glomax $\mathrm{Multi}^{+}$combined spectro-fluoro-luminometer (Promega, Madison, USA) using the appropriate filter settings. The results are displayed as the ratio of JC-1 polymers to JC-1 monomers (JC-1 units).

\section{Viability evaluation}

For the membrane integrity analysis $1 \times 10^{6}$ cells were pipetted into a vial, diluted to $100 \mu \mathrm{L}$ with PBS, followed by $10 \mu \mathrm{L}$ CFDA (carboxyfluorescein diacetate; Sigma-Aldrich, St. Louis, USA; $0.75 \mathrm{mg} / \mathrm{mL}$ in DMSO), $10 \mu \mathrm{L}$ PI (propidium iodide; Sigma-Aldrich, St. Louis, USA; $2 \mathrm{mg} / \mathrm{mL}$ in H2O) and $10 \mu \mathrm{L}$ DAPI (4',6diamidino-2-phenylindole; Sigma-Aldrich, St. Louis, USA; $1 \mu \mathrm{mol} / \mathrm{L}$ in PBS) The samples were incubated for $15 \mathrm{~min}$ at $37{ }^{\circ} \mathrm{C}$ in the dark. Subsequently, the samples were centrifuged for $5 \mathrm{~min}$ at $2100 \mathrm{RPM}$. After centrifugation, the resulting supernatant was carefully removed and the cells were washed with 100 $\mu \mathrm{L}$ PBS. The centrifugation and washing step was repeated and the cells were resuspended with $100 \mu \mathrm{L}$ PBS. The samples were transferred to a 96-well plate and analyzed using the Glomax Multi $^{+}$combined spectro-fluoro-luminometer using the appropriate filter settings. CFDA-positive cells were considered to be membrane-intact (\%), while PI-positive cells were displayed as apoptotic/necrotic (\%).

\section{Acrosome integrity}

For the analysis of the acrosome integrity, $1 \times 10^{6}$ cells were transferred to a via and diluted to $100 \mu \mathrm{L}$ using PBS, followed by $100 \mu \mathrm{L}$ PNA (peanut agglutinin, FITC conjugate; Sigma-Aldrich, St. Louis, USA; $10 \mu \mathrm{mol} / \mathrm{L}$ in PBS) and $10 \mu \mathrm{L}$ DAPI. The samples were incubated for $30 \mathrm{~min}$ at $37^{\circ} \mathrm{C}$. After incubation, $200 \mu \mathrm{L}$ sample were placed into a 96-well plate and analyzed using the Glomax Multi+ combined spectro-fluoro-luminometer (Promega, Madison, USA) using the appropriate filter settings. PNA-negative cells were considered to be acrosomeintact $(\%)$.

\section{Statistical analysis}

Statistical analysis was carried out using the GraphPad Prism program (version 5.02 for Windows; GraphPad Software, La Jolla California USA, www.graphpad.com). Descriptive statistical characteristics (mean, standard error) were evaluated at first. One-way ANOVA with Dunnett's post test was used for advanced statistical evaluations. The level of significance was set at ${ }^{* * *} \mathrm{P}<0.001$; ${ }^{* *} \mathrm{P}<0.01 ;{ }^{*} \mathrm{P}<0.05$

\section{RESULTS}

\section{Sperm motility}

Data obtained from the CASA analysis are shown in Figure 1. The administration of $10 \mu \mathrm{mol} / \mathrm{L}$ RES led to a significant preservation of the mouse spermatozoa motility immedialely following the sperm release from the epididymis (time $0 \mathrm{~h} ; \mathrm{P}<0.05$ ). Similar results were recorded following a $2 \mathrm{~h}$ incubation, with a significantly higher motility detected in the experimental groups exposed to $10 \mu \mathrm{mol} / \mathrm{L}$ RES $(\mathrm{P}<0.01)$ and $25 \mu \mathrm{mol} / \mathrm{L}$ RES $(\mathrm{P}<0.05)$ when compared to the control.

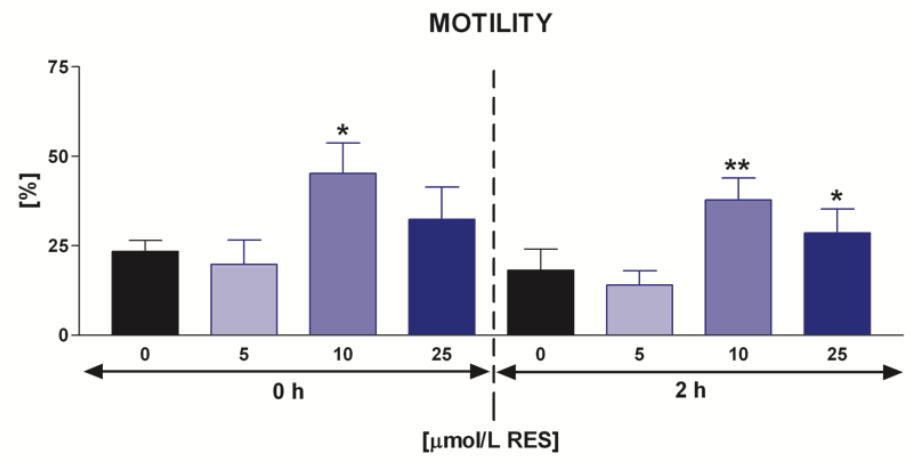

Figure 1 The impact of selected RES concentrations on mouse spermatozoa motility (\%) during two time periods. Mean \pm SEM. ${ }^{*} \mathrm{P}<0.05 ;{ }^{* *} \mathrm{P}<0.01$.

\section{Mitochondrial activity}

As seen in Figure 2, the fluorimetric assessment of the mitochondrial activity revealed a significant increase of the MMP in the experimental group supplemeted with $10 \mu \mathrm{mol} / \mathrm{L}$ RES $(\mathrm{P}<0.05)$ in comparison with the control following the sperm collection. Beneficial effects of $10 \mu \mathrm{mol} / \mathrm{L}$ RES on the mitochondrial activity were furthermore confirmed at time $2 \mathrm{~h}$, with a signnificantly higher MMP $(\mathrm{P}<0.05)$ when compared to the control group.

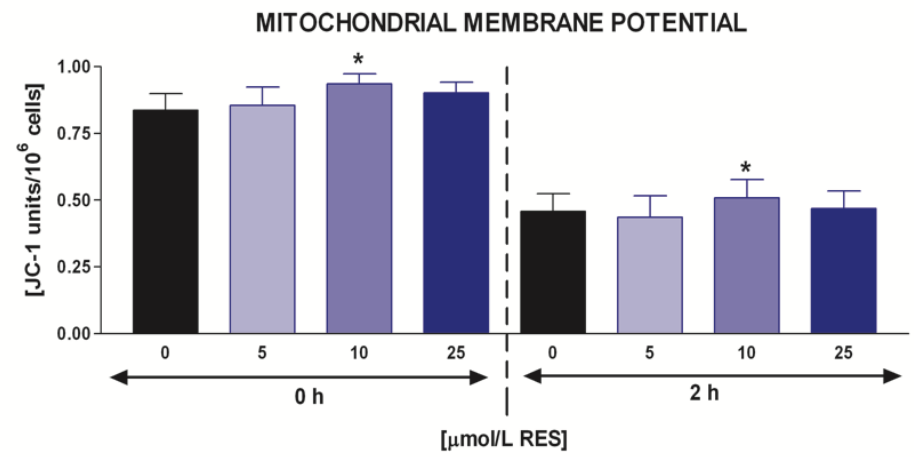

Figure 2 The impact of selected RES concentrations on the mitochondrial membrane potential (JC1 units) of mouse spermatozoa during two time periods. Mean \pm SEM. ${ }^{*} \mathrm{P}<0.05$

\section{Viability and necrosis evaluation}

Figure 3 depicts the in vitro effects of RES on the membrane integrity of epididymal mouse spermatozoa. Although no significant positive or negative impact of RES on the membrane stability was recorded immediately following the sperm swim-out procedure, a significantly higher preservation of the integrity of the sperm plasma membranes was detected following $2 \mathrm{~h}$ of in vitro culture, particularly in the case of $10 \mu \mathrm{mol} / \mathrm{L}(\mathrm{P}<0.01)$ and $25 \mu \mathrm{mol} / \mathrm{L}$ RES $(\mathrm{P}<0.05)$. 


\section{MEMBRANE INTEGRITY}

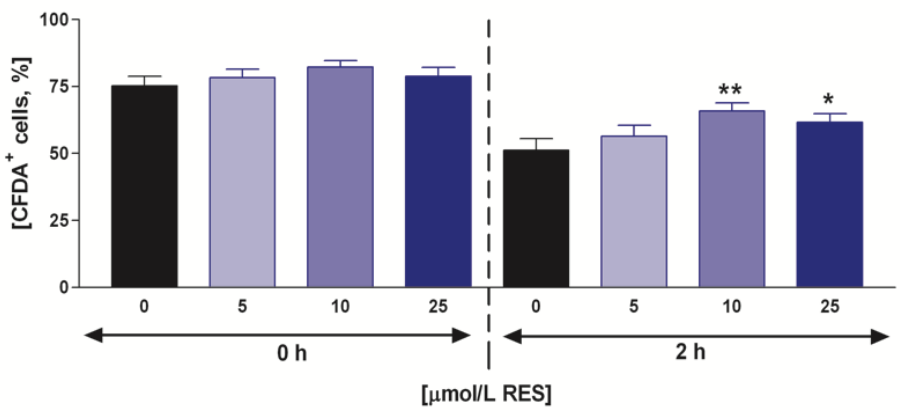

Figure 3 The impact of selected RES concentrations on the membrane integrity $(\%)$ of mouse spermatozoa during two time periods. Mean \pm SEM. ${ }^{*} \mathrm{P}<0.05 ;{ }^{*}$ $\mathrm{P}<0.01$.

To detect any necrotic changes to the epididymal spermatozoa under the influence of RES, the cells were stained with PI and assessed using fluorimetry. The analyses detected a time-dependent increase of PI-positive sperm cells. Nevertheless, RES administration had no impact on the percentage of necrotic cells neither at baseline, nor following $2 \mathrm{~h}$ of in vitro incubation. A decreasing trend of apoptotic and/or necrotic changes in spermatozoa was observed following the administration of all RES doses at time $2 \mathrm{~h}$, however the changes were not statistically significant $(\mathrm{P}>0.05$; Figure 4$)$.

\section{NECROTIC CELLS}

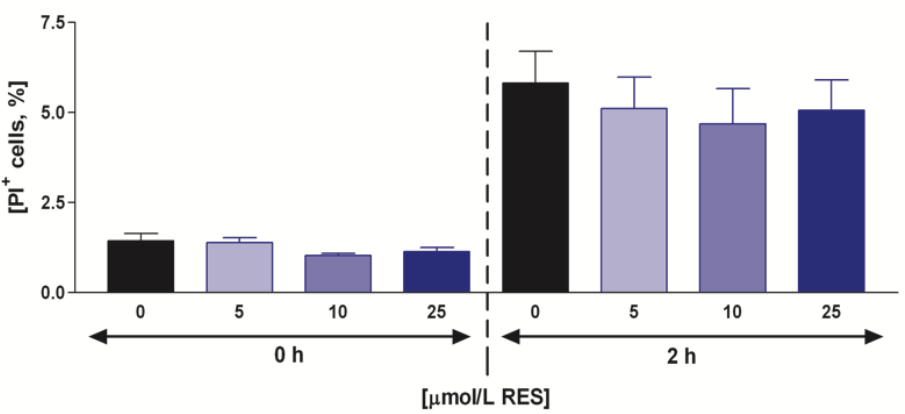

Figure 4 The impact of selected RES concentrations on the on the occurrence of necrotic mouse spermatozoa (\%). Mean \pm SEM.

\section{Acrosome integrity}

Data collected from the assessment of the acrosome integrity using the fluorescent PNA staining method and displayed in Figure 5 revealed an instant protective effect of RES, particularly at a dose of $10 \mu \mathrm{mol} / \mathrm{L}$ on the stability of acrosomal structures $(\mathrm{P}<0.05$; time $0 \mathrm{~h})$. This protection lasted throughout the in vitro incubation, leading to a significantly higher acrosome integrity of mouse spermatozoa exposed to $10 \mu \mathrm{mol} / \mathrm{L}$ RES in comparison with the control $(\mathrm{P}<0.05$; time $2 \mathrm{~h}$ ).

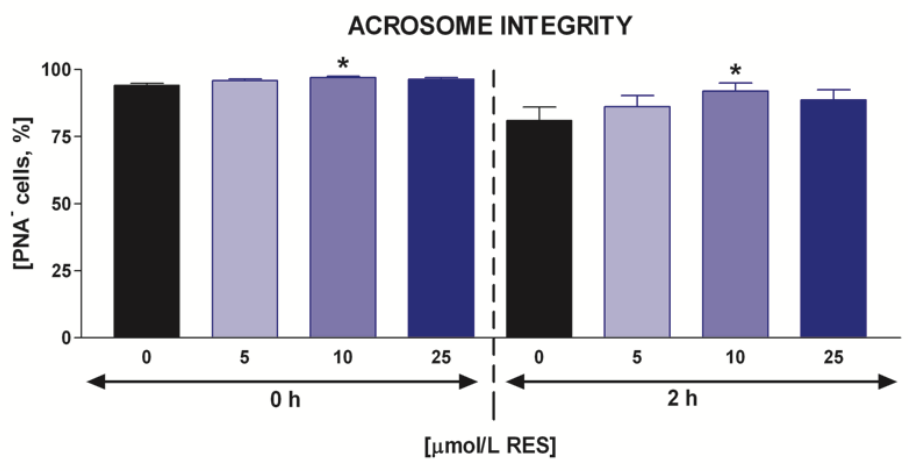

Figure 5 The impact of selected RES concentrations on the on the acrosome integrity of mouse epididymal spermatozoa (\%). Mean \pm SEM. ${ }^{* *} \mathrm{P}<0.01$.

\section{DISCUSSION}

Currently, a significant body of evidence reflects on the beneficial aspects of RES in human and animal health. Attention driven towards this molecule has increased since it has been shown to possess numerous biological attributes, such as antibacterial, antioxidant, anti-inflammatory and chemopreventive properties (de la Rastra and Villegas, 2007). However, numerous in vitro studies have reported that RES exhibits dose-dependent effects on mammalian cells, demonstrating an interesting dichotomy: low doses may improve the cell survival, while high doses could contribute to an increased cell death (Salehi $\boldsymbol{e}$ al., 2018).

RES administration in this report resulted in an enhancement and/or stabilization of mouse spermatozoa motility and viability over the in vitro cultivation period. Nevertheless, our results contradict Collodel et al. (2011) who examined the impact of RES on the motility of swim-up selected sperm. At $100 \mu \mathrm{mol} / \mathrm{L} \mathrm{RES}$, the motility was absent in all assessed samples, whereas the progressive motility reached its maximum at 6 and $15 \mu \mathrm{mol} / \mathrm{L}$ of RES. Talking in favor of our data, our previous observations (Tvrdá et al., 2015a;b) did suggest protective effects of RES on bovine sperm motion characteristics, when incubated over a period of $24 \mathrm{~h}$ or in the presence of a potent prooxidant, although we must agree that in case of a broader concentration range, RES may act dose dependently as either a stimulant at low doses or as an inhibitor at high doses. This controversy was furthermore assessed by Tvrdá et al. (2015b) revealing that 100 and $200 \mu \mathrm{mol} / \mathrm{L}$ RES did not per se exhibit lethal effects on the bovine spermatozoa viability, however its presence suppressed all sperm activity parameters.

The selected RES concentration range in this study oscillated between 5 to 25 $\mu \mathrm{mol} / \mathrm{L}$, which are believed to be adequate for mouse spermatozoa motility preservation (Mojica-Villegas et al., 2014; Rodriguez et al., 2016). Our CASA and MMP data agree with Mojica-Villegas et al. (2014), who reported that a pretreatment with $15 \mathrm{mg} / \mathrm{mL}$ RES $15 \mathrm{~min}$ before incubation with ferrous ascorbate (FeAA) showed an 8.0-fold increase in murine spermatozoa motility and a 2.0-fold increase in their viability. Tvrdá et al. (2015a) reported that supplementation of RES led to a significant preservation of washed-out bovine spermatozoa, maintaining a higher percentage of motile sperm over the course of a $6 \mathrm{~h}$ cultivation. Furthermore, RES administration to spermatozoa exposed to FeAA led to a significant improvement of the spermatozoa motion behavior in spite of the toxic effects of the prooxidant.

On the other hand, Silva et al. (2012) reported that RES administration before sperm cryopreservation did not exhibit any significant effect on the motility, plasma membrane or acrosome integrity of ram spermatozoa. What is more human sperm motility declined following cryopreservation in the presence of RES in comparison with to the control in the reports by Pasqualotto et al. (2006) and Garcez et al. (2010). Inversely, Sarlos et al. (2002) reported a higher motility and acrosome integrity of ram spermatozoa in the presence of RES following their storage at $5{ }^{\circ} \mathrm{C}$ for 6 days. Similar results were reported by Collodel $\boldsymbol{e t}$ al. (2011) observed that low RES doses led to a higher progressive motility of swim-up selected human spermatozoa.

Spermatozoa motility has been linked with the functional status of mitochondria on numerous occasions, as motility is ATP-dependent. Results by MojicaVillegas et al. (2014) focused on the effect of RES on the mitochondrial membrane potential (MMP) on mouse spermatozoa showed that pretreatment with RES provided protection to the male gametes against the decrease in the mitochondrial activity caused by FeAA. In the meantime, it has been revealed that MMP was modulated by RES in a concentration-dependent manner without affecting motility, acrosome integrity or plasma membrane fluidity in frozenthawed ram spermatozoa (Silva et al., 2012). The mitochondrial system is the main source of intracellular ROS, where the respiratory chain plays roles in an autoxidation process (Moretti et al., 2012). In the meantime, RES may contribute to ROS absorption and neutralization, because of its unique chemical properties, its ability to inhibit ROS production by enzymatic and non-enzymatic systems, especially NADPH oxidase and NADH-dependent oxidoreductase, localized in the sperm plasma membrane and mitochondria (Truong et al., 2018) In a recent report assessment of the effect of RES on ram spermatozoa during cryopreservation, it was shown that this polyphenol was able to modulate the mitochondrial membrane potential (Silva et al., 2012), which might reflect on our JC1 data. Affecting calcium influx to spermatozoa is another possible mechanism by which RES maintains the ATP concentration in spermatozoa (MartinHidalgo et al., 2013), prevents premature capacitation and acrosome reaction $(\mathbf{L i}$ et al., 2018) during sperm storage, and enhances sperm longevity by saving its limited energy content. At the same time, as observed by Tvrdá et al. (2015a), RES was capable to prevent mitochondrial dysfunction as a consequence of FeAA-associated oxidative damage. Resveratrol was particularly effective in protecting the spermatozoon through the protection and maintenance of spermatozoa metabolism as reflected by the mitochondrial metabolic (MTT) test. The structural determinants of these diverse properties of the resveratrol molecule are obscure, but the number and position of the hydroxylic groups have been suggested to play an important role in the antioxidant activity. $4^{\prime}$-hydroxyl group in trans-conformation (hydroxystyryl moiety) is required for the antioxidant activity but acts synergistically with the $3-$ and 5-OH groups (Stivala et al., 2011). Additionally, QUE may be effective because of its ability to interact with 
and penetrate through lipid bilayers. A notable RES property is its antioxidant potential, as it is able to reach peroxidized rigid membranes and to increase the membrane fluidity in order to interact more efficiently with radicals in the altered lipid bilayer (Tadolini et al., 2000). At the same time Lagouge et al. (2006) proved that the effects of small concentrations of RES were associated with an induction of genes responsible for oxidative phosphorylation and mitochondrial biogenesis, therefore promoting mitochondrial functions of the cell, based on what we may hypothesize that small concentrations of RES could boost the energetic metabolism of male gametes and thus improve their vitality.

Protective effects of RES on the membrane and acrosome integrity of mouse spermatozoa observed in this study agrees with Longobardi et al. (2017) and Najafi et al. (2019) who reported on a significant preservation of the membrane integrity and a reduction of apoptotic changes in cryopreserved buffalo and rooster spermatozoa following administration of $50 \mu \mathrm{mol} / \mathrm{L}$ RES and $40 \mu \mathrm{mol} / \mathrm{L}$ RES respectively. Similarly, Li et al. (2018) reported on a higher acrosomal integrity of bovine sex-sorted spermatozoa following exposure to $10^{-4} \mathrm{mmol} / \mathrm{L}$ RES. It has been well described that ROS overproduction during semen processing may exhibit detrimental effects on the membranous structure and acrosome of male reproductive cells (Rui et al., 2017). Moreover, polyunsaturated fatty acids (PUFAs) located in spermatozoa are sensitive to oxidative insults, resulting in lipid peroxidation (LPO) and changes to the liquidity and integrity of membranes, leading to acrosome breakage and leakage of the contents, culminating in altered sperm-egg interactions (Zhang et al., 2017)

All beneficial effects of RES on the stability of membranous structures resulting from our experiments are most likely related to the suppression of LPO of membranous structures (Tadolini et al., 2000), an event which has been shown to be coupled with the loss of sperm structural integrity and functional activity. It has been reported on numerous occasions that RES exhibits protective effects against LPO in cell membranes of animal spermatozoa (Longobardi et al., 2017; Li et al., 2018; Najafi et al., 2019). Polyphenols are ought to be easily incorporated into the membrane lipid bilayer (Tadolini et al., 2000), inhibiting the formation of lipid radicals and protecting the membrane integrity and electrolytic equilibrium of the sperm cell (Aitken et al., 2016). Hence fluorimetric and colorimetric analyses had been carried out in previous studies in order to confirm the above-described hypothesis. Results collected from studies on other mammalian species indicate that RES was effective in preventing LPO, suggesting that the protective effects of RES against oxidative insults to the sperm lipids might be attributed to a hydrogen electron donation from its hydroxyl groups (Tadolini et al., 2000; Stivala et al., 2011).

In the meantime, it has been shown that RES may play important roles in preventing premature sperm capacitation and, consequently, acrosome reaction (Sarlos et al., 2002; Li et al., 2018). Taken together, this evidence may help to understand the higher percentage of mouse spermatozoa in which the integrity of the membranes and acrosome is preserved.

Finally, it should be noticed that RES has the ability to exhibit both antioxidant as well as prooxidant properties. Depending on the concentration of the phytoalexin and the cell type, it has been shown that resveratrol could promote ROS overproduction leading to oxidative stress, associated with oxidative breakage of cellular proteins, lipids and DNA in the presence of transition metal ions such as copper (de la Rastra and Villegas, 2007). As such, divergent results with RES and male reproductive performance may be attributed to severa factors, including the species, semen extender, dosage, method of administration, as well as variable half-life among ROS, which all may modulate its definitive actions.

\section{CONCLUSION}

Our results, even though preliminary, support the evidence for membraneprotecting and motility promoting in vitro activity of resveratrol concentrations oscillating around $10 \mu \mathrm{mol} / \mathrm{L}$ in mouse epididymal spermatozoa. The development of new sperm washing and preservation media providing a better selective advantage to the survival of male gametes as well as improvement of their energy requirements is of great interest. Resveratrol, in specific amounts, could be used as a motility and metabolism-promoting supplement, especially in laboratory techniques aimed for the reproduction of rodents, including sperm retrieval, in vitro fertilization, artificial insemination and sperm cryopreservation.

Acknowledgments: This study was supported by the European Community Project no. 26220220180: Building Research Centre "AgroBioTech", by the KEGA Project no. 009SPU-4/2018, and by the Slovak Research and Development Agency Grant no. APVV-15-0544. Experiments of this study were performed with support of the "CeRA" Team of Excellence.

\section{REFERENCES}

Aitken, R. J., Muscio, L., Whiting, S., Connaughton, H. S., Fraser, B. A., Nixon, B., Smith, N. D. \& De Iuliis, G. N. (2016). Analysis of the effects of polyphenols on human spermatozoa reveals unexpected impacts on mitochondrial membrane potential, oxidative stress and DNA integrity; implications for assisted reproductive technology. Biochemical Pharmacology, 121, 78-96. https://doi.org/10.1016/i.bcp.2016.09.015

Bansal, A. K. \& Bilaspuri, G. S. (2010). Impacts of oxidative stress and antioxidants on semen functions. Veterinary Medicine International, 2010, 686137. http://dx.doi.org/10.4061/2011/686137.

Bolker J. (2012). Model organisms: There's more to life than rats and flies. Nature, 491(7422), 31-33. http://dx.doi.org/10.1038/491031a.

Collodel, G., Federico, M. G., Geminiani, M., Martini, S., Bonechi, C., Rossi, C., Figura, N. \& Moretti E. (2011). Effect of trans-resveratrol on induced oxidative stress in human sperm and in rat germinal cells. Reproductive Toxicology, 31, 2 , 239-246. http://dx.doi.org/10.1016/j.reprotox.2010.11.010

de la Rastra, C. A. \& Villegas, I. (2007). Resveratrol as an antioxidant and prooxidant agent: mechanisms and clinical implications. Biochemical Society Transactions, 35, 1156-1160.

du Plessis S. S., Makker, K., Desai, N. R. \& Agarwal, A. (2008). Impact of oxidative stress on IVF. Expert Review of Obstetrics \& Gynecology, 3, 539-554. Gambini, J., Inglés, M., Olaso, G., Lopez-Grueso, R., Bonet-Costa, V., GimenoMallench, L., Mas-Bargues, C., Abdelaziz, K. M., Gomez-Cabrera, M. C., Vina, J. \& Borras, C. (2015). Properties of resveratrol: in vitro and in vivo studies about metabolism, bioavailability, and biological effects in animal models and humans. Oxidative Medicine and Cellular Longevity, 2015, 837042 http://dx.doi.org/10.1155/2015/837042

Garcez, M. E., dos Santos Branco, C., Lara, L.V., Pasqualotto, F. F. \& Salvador, M. (2010). Effects of resveratrol supplementation on cryopreservation medium of human semen. Fertility and Sterility, 94, 2118-2121. https://doi.org/10.1016/j.fertnstert.2010.01.058

Gibb, Z. \& Aitken, R. J. (2016). The impact of sperm metabolism during in vitro storage: the stallion as a model. BioMed Research International, 2016, 9380609. https://doi.org/10.1155/2016/9380609.

Jiang, Y., Penh, T., Luo, Y., Li, M. \& Lin, Y. (2008). Resveratrol reestablishes spermatogenesis after testicular injury in rats caused by 2,5- hexanedione. Chinese Medical Journal, 121, 1204-1209.

Juan, M. E., Gonzales-Pons, E., Munuera, T., Ballester, J., Rodriguez-Gil, J. E. \& Planas, J. M. (2005). Trans-resveratrol, a natural antioxidant from grapes, increases sperm output in healthy rats. Journal of Nutrition, 135, 757-760.

Khan, M. A., Chen, H. C., Wan, X. X., Tania, M., Xu, A. H., Chen, F. Z. \& Zhang, D. Z. (2013). Regulatory effects of resveratrol on antioxidant enzymes: a mechanism of growth inhibition and apoptosis induction in cancer cells Molecules and Cells, 35(3), 219-225. http://dx.doi.org/10.1007/s10059-013$\underline{2259-\mathrm{z}}$

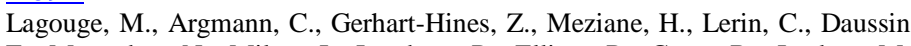
F., Messadeq, N., Milne, J., Lambert, P., Elliott, P., Geny, B., Laakso, M., Puigserver, P. \& Auwerx, J. (2006). Resveratrol improves mitochondrial function and protects against metabolic disease by activating SIRT1 and PGC-1alpha Cell, 127, 6, 1109-1122.

Li, C. Y., Zhao, Y. H., Hao, H. S., Wang, H. Y., Huang, J. M., Yan, C. L., Du, W. H., Pang, Y. W., Zhang, P. P., Liu, Y., Zhu, H. B. \& Zhao, X. M. (2018). Resveratrol significantly improves the fertilisation capacity of bovine sex-sorted semen by inhibiting apoptosis and lipid peroxidation. Scientific Reports, 8, 1, 7603. https://doi.org/10.1038/s41598-018-25687-z

Martin-Hidalgo, D., de Llera, A. H., Henning, H., Wallner, U., Waberski, D., Bragado, M. J., Gil, M. C. \& Garcia-Marin, L. J. (2013). The effect of resveratrol on the quality of extended boar semen during storage at $17{ }^{\circ} \mathrm{C}$. Journal of Agricultural Science, 5, 8, 231-242.

Mojica-Villegas, M. A., Izquierdo-Vega, J. A., Chamorro Cevallos, G. \& Sanchez-Guiterrez, M. (2014). Protective effect of resveratrol on biomarkers of oxidative stress induced by iron/ascorbate in mouse spermatozoa. Nutrients, 6 , 489-503. http://dx.doi.org/10.3390/nu6020489

Moretti, E., Mazzi, L., Terzuoli, G., Bonechi, C., Iacoponi, F., Martini, S., Rossi, C. \& Collodel, G. (2012). Effect of quercetin, rutin, naringenin and epicatechin on lipid peroxidation induced in human sperm. Reproductive Toxicology, 34, 651-657. https://doi.org/10.1016/i.reprotox.2012.10.002

Mouse Genome Sequencing Consortium, Waterston, R. H., Lindblad-Toh, K. Birney, E., Rogers, J., Abril, J. F., Agarwal, P., Agarwala, R., Ainscough, R., Alexandersson, M., An, P., Antonarakis, S. E., Attwood, J., Baertsch, R., Bailey, J., Barlow, K., Beck, S., Berry, E., Birren, B., Bloom, T., Bork, P., Botcherby, M., Bray, N., Brent, M. R, Brown, D. G., Brown, S. D., Bult, C., Burton, J., Butler, J., Campbell, R. D., Carninci, P., Cawley, S., Chiaromonte, F., Chinwalla, A. T., Church, D. M., Clamp, M., Clee, C., Collins, F. S., Cook, L. L., Copley, R. R., Coulson, A., Couronne, O., Cuff, J., Curwen, V., Cutts, T., Daly, M., David, R., Davies, J., Delehaunty, K. D., Deri, J., Dermitzakis, E. T., Dewey, C., Dickens, N. J., Diekhans, M., Dodge, S., Dubchak, I., Dunn, D. M., Eddy, S. R., Elnitski, L., Emes, R. D., Eswara, P., Eyras, E., Felsenfeld, A, Fewell, G. A. Flicek, P., Foley, K., Frankel, W. N., Fulton, L. A., Fulton, R. S., Furey, T. S., Gage, D., Gibbs, R. A., Glusman, G., Gnerre, S., Goldman, N., Goodstadt, L., Grafham, D., Graves, T. A., Green, E. D., Gregory, S., Guigó, R., Guyer, M. Hardison, R. C., Haussler, D., Hayashizaki, Y., Hillier, L. W., Hinrichs, A., Hlavina, W., Holzer, T., Hsu, F., Hua, A., Hubbard, T., Hunt, A., Jackson, I., Jaffe, D. B., Johnson, L. S., Jones, M., Jones, T. A., Joy, A., Kamal, M., Karlsson, E. K., Karolchik, D., Kasprzyk, A., Kawai, J., Keibler, E., Kells, C. 
Kent, W. J., Kirby, A., Kolbe, D. L., Korf, I., Kucherlapati, R. S., Kulbokas, E. J., Kulp, D., Landers, T., Leger, J. P., Leonard, S., Letunic, I., Levine, R., Li, J., Li, M., Lloyd, C., Lucas, S., Ma, B., Maglott, D. R., Mardis, E. R., Matthews, L., Mauceli, E., Mayer, J. H., McCarthy, M., McCombie, W. R., McLaren, S., McLay, K., McPherson, J. D., Meldrim, J., Meredith, B., Mesirov, J. P., Miller, W., Miner, T. L., Mongin, E., Montgomery, K. T., Morgan, M., Mott, R., Mullikin, J. C., Muzny, D. M., Nash, W. E., Nelson, J. O., Nhan, M. N., Nicol, R., Ning, Z., Nusbaum, C., O'Connor, M. J., Okazaki, Y., Oliver, K., OvertonLarty, E., Pachter, L., Parra, G., Pepin, K. H., Peterson, J., Pevzner, P., Plumb, R., Pohl, C. S., Poliakov, A., Ponce, T. C., Ponting, C. P., Potter, S., Quail, M. Reymond, A., Roe, B. A., Roskin, K. M., Rubin, E. M., Rust, A. G., Santos, R., Sapojnikov, V., Schultz, B., Schultz, J., Schwartz, M. S., Schwartz, S., Scott, C., Seaman, S., Searle, S., Sharpe, T., Sheridan, A., Shownkeen, R., Sims, S., Singer, J. B., Slater, G., Smit, A., Smith, D. R., Spencer, B., Stabenau, A., StangeThomann, N., Sugnet, C., Suyama, M., Tesler, G., Thompson, J., Torrents, D. Trevaskis, E., Tromp, J., Ucla, C., Ureta-Vidal, A., Vinson, J. P., Von Niederhausern, A. C., Wade, C. M., Wall, M., Weber, R. J., Weiss, R. B., Wendl, M. C., West, A. P., Wetterstrand, K., Wheeler, R., Whelan, S., Wierzbowski, J. Willey, D., Williams, S., Wilson, R. K., Winter, E., Worley, K. C., Wyman, D., Yang, S., Yang, S. P., Zdobnov, E. M., Zody, M. C. \& Lander, E. S. (2001) Initial sequencing and comparative analysis of the mouse genome. Nature, 420(6915), 520-562.

Pandey, K. B. \& Rizvi, S. I. (2011). Anti-oxidative action of resveratrol Implications for human health. Arabian Journal of Chemistry, 4(3), 293-298.

Pasqualotto, F. F., Garcez, M., Borges, E., Gupta, S., Salvador, M. \& Agarwal, A. (2006). Lipid peroxidation, superoxide dismutase, catalase levels and sperm motility: protective role of vitamin $\mathrm{C}$ and resveratrol prior to sperm

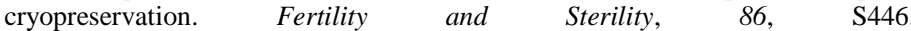
https://doi.org/10.1016/j.fertnstert.2006.07.1232

Peña, F.J., Rodríguez Martínez, H., Tapia, J.A., Ortega Ferrusola, C., González Fernández, L. \& Macías García, B. (2009). Mitochondria in mammalian sperm physiology and pathology: a review. Reproduction in Domestic Animals, 44, 345 349. http://dx.doi.org/10.1111/j.1439-0531.2008.01211.x

Perlman, R. L. (2016). Mouse models of human disease: An evolutionary perspective. Evolution, medicine, and public health, 2016(1), 170-176. http://dx.doi.org/10.1093/emph/eow014

Revel, A., Raanani, H., Younglai, E., Xu, J., Han, R., Savouret, J. F. \& Casper, R. F. (2001). Resveratrol, a natural aryl hydrocarbon receptor antagonist, protects sperm from DNA damage and apoptosis caused by benzo(a)pyrene. Reproductive Toxicology, 15, 479-486.

Rodriguez, I., Diaz, A. \& Vaamonde, D. (2016). Assessment of the effect of prolonged forced swimming on CD-1 mice sperm morphology with and without antioxidant supplementation. Andrologia, 48, 3, 277-281. http://dx.doi.org/10.1111/and.12443

Rui, B. R., Shibuya, F. Y., Kawaoku, A. J. T., Losano, J. D. A., Angrimani, D. S. R., Dalmazzo, A., Nichi, M. \& Pereira, R. J. G. (2017). Impact of induced levels of specific free radicals and malondialdehyde on chicken semen quality and $\begin{array}{llll}\text { fertility. } & \text { Theriogenology, } & \text { 11-19. }\end{array}$ https://doi.org/10.1016/j.theriogenology.2016.11.001

Saiki, R. K., Gelfand, D. H., Stoffel, S., Scharf, S. J., Higuchi, R., Horn, G. T., .. \& Erlich, H. A. (1988). Primer-directed enzymatic amplification of DNA with a thermostable DNA polymerase. Science, 239(4839), 487 491.http://dx.doi.org/10.1088/1367-2630/1/1/006

Salehi, B., Mishra, A. P., Nigam, M., Sener, B., Kilic, M., Sharifi-Rad, M. Fokou, P. V. T., Martins, N. \& Sharifi-Rad, J. (2018). Resveratrol: A DoubleEdged Sword in Health Benefits. Biomedicines, 6(3), 91 http://dx.doi.org/10.3390/biomedicines6030091

Sarlos, P., Molnar, A., Kokai, M., Gabor, G. \& Ratky, J. (2002). Comparative evaluation of the effect of antioxidants in the conservation of ram semen. Acta Veterinaria Hungarica, 50, 235-245.

Shin, S., Jeon, J. H., Park, D., Jang, M. J., Choi, J. H., Choi, B. H., Joo, S. S., Nahm, S. S., Kim, J. C. \& Kim, Y. B. (2008). Trans-resveratrol relaxes the corpus cavernosum ex vivo and enhances testosterone levels and sperm quality in vivo. Archives of Pharmacal Research, 31(1), 83-87.

Silva, E. C., Cajueiro, J. F., Silva, S. V., Soares, P. C. \& Guerra, M. M. (2012) Effect of antioxidants resveratrol and quercetin on in vitro evaluation of frozen $\begin{array}{llll}\text { ram } & \text { sperm. } & \text { Theriogenology, } & 7722-1726\end{array}$ https://doi.org/10.1016/j.theriogenology.2011

Stivala, L. A., Savio, M., Carafoli, F., Perucca, P., Bianchi, L., Maga, G., Forti, L., Pagnoni, U. M., Albini, A., Prosperi, E. \& Vannini, V. (2001). Specific structural determinants are responsible for the antioxidant activity and the cell cycle effects of resveratrol. Journal of Biological Chemistry, 276, 25, 2258622594.

Tadolini, B., Juliano, C., Piu, L., Franconi, F. \& Cabrini L. (2000). Resveratrol inhibition of lipid peroxidation. Free Radical Research, 33(1), 105-114.

Takahashi, H. \& Liu, C. (2010). Archiving and distributing mouse lines by sperm cryopreservation, IVF, and embryo transfer. Methods in Enzymology, 476, 53-69. http://dx.doi.org/10.1016/S0076-6879(10)76004-3.
Truong, V. L., Jun, M. \& Jeong, W. S. (2018). Role of resveratrol in regulation of cellular defense systems against oxidative stress. Biofactors, 44, 1, 36-49. https://doi.org/10.1002/biof.1399

Tvrdá, E., Kováčik, A., Tušimová, E., Massányi, P. \& Lukáč, N. (2015a). Resveratrol offers protection to oxidative stress induced by ferrous ascorbate in bovine sprmatozoa. Journal of Environmental Science and Health, Part A 50(14), 1440-1451. http://dx.doi.org/10.1080/10934529.2015.1071153

Tvrdá, E., Lukáč, N., Lukáčová, J., Hashim, F. \& Massányi, P. (2015b). In vitro supplementation of resveratrol to bovine spermatozoa: effects on motility, viability and superoxide production. Journal of Microbiology, Biotechnology and Food Sciences, 4, 4, 336-341. http://dx.doi.org/10.15414/jmbfs.2015.4.4.336-341 Zhang, X. G., Li, H., Wang, L., Hao, Y. Y., Liang, G. D., Ma, Y. H., Yang, G. S \& Hu, J. H. (2017). The effects of different levels of superoxide dismutase in Modena on boar semen quality during liquid preservation at 17 degrees $\mathrm{C}$. Animal Science Journal, 88, 55-62. https://doi.org/10.1111/asj.12574 